\title{
A Study on HR Analytics Transforming Human Resource Management
}

\author{
Asim Kumar Rajbhar, Tarannum Khan, Sudhakar Puskar
}

Department of Rural Management, School of Management Studies, Baba Saheb Bhirao Ambedkar University, Lucknow, India

Email address:

akrbharan@gmail.com (A. K. Rajbhar), tarannumkhan19oct@gmail.com (T. Khan), sudhakar.puskar@gmail.com (S. Puskar)

To cite this article:

Asim Kumar Rajbhar, Tarannum Khan, Sudhakar Puskar. A Study on HR Analytics Transforming Human Resource Management. Journal of Investment and Management. Vol. 6, No. 4, 2017, pp. 92-96. doi: 10.11648/j.jim.20170604.12

Received: July 1, 2017; Accepted: July 24, 2017; Published: November 28, 2017

\begin{abstract}
Human resources have continually been the important asset of the organization. To have an aggressive aspect, employees ought to be handled as sources and accordingly with the aid of aligning human resource feature to the central business dreams, corporations can achieve achievement within the competitive marketplace. Human sources are always at the very center of the employer's fulfillment. HR analytic's performs a totally vital function in aligning the $\mathrm{HR}^{1}$ analytic's with the general business strategy. HR analytics aids the HR managers to formulate the strategies which enable the corporation to benefit a top hand over its competitors. The papers analyze whether HR analytics is Transmuting the Human resource department and the HR managers. The study examines how HR Analytics facilitates the improvement of a group of workers overall performance in a corporation consequently growing the productiveness of the employees in turn growing revenue technology. The paper also consists of the case have a look at a technique which depicts HR analytics because of the slicing edge device for human useful resource management and not a mere hype.
\end{abstract}

Keywords: HR Analytics, Personnel Analytics, Human Resource Management, Talent Control, Talent Acquisition

\section{Introduction}

Human useful resource control performs a critical component in any organization. Human useful resource management is a function of the enterprise specifically estimated to capitalize on the worker's overall performance in a carrier of a business enterprise's strategic dreams. The winning monetary set-up is forcing Human useful resource Managers to emphasise their interest on its personnel overall performance for generating returns for the business. but as worldwide financial and political settings are converting, it has started to worry the corporate leaders, and as a result their attention has become to the various gadgets which could nurture achievement in unsure times. In the modern rapid emergent financial system, the opposition has intensified among corporations. To gain a sturdy competitive edge, corporations ought to align their HR approach with their usual enterprise method. No functional area of any agency can characteristic without the help of human resources. hence human assets integrally have an effect on the overall approach of the business enterprise. Humans are the greatest aid an organisation will have. hence, human useful resource control is that a part of the corporation which is involved with the "people" thing (De Cenzo and Robbins, 1996). each employer is essentially produced from its people. And ensuring their productivity remains profitable to the enterprise is the process of the HRM. as the financial scenario keeps on changing because of globalization, Human resource branch also desires to adapt to this new trade. hence, preserving pinnacle competencies is the primary problem for the HR these days. better employee engagement and maintaining strategies are the need of the hour. as an instance, HR today is in particular focused on the execution of approach within the form of downsizing and restructuring techniques through outplacing worker performance related pay rules, reducing well-being care overheads and retraining employees. for this reason, even inside the increasingly more competitive surroundings these days, establishing HR practices that construct employee dedication can assist increase businesses responsiveness. The success of the

${ }^{1} \mathrm{HR}=$ Human Resource 
organization relies upon on is human beings. Human assets assist in coping and living to tell the tale within the midst of fast developing and speedy changing socio- monetary surroundings through exploiting commercial enterprise possibility with the minimal risk and challenges. as a result, humans arc crucially important and provide a strategic advantage in the fiercely competitive market.

\section{Challenges Faced by Human Resource Department}

The rapid monetary changes and globalization, Human resources department has been regularly tacit challenges and is in steady catch 22 situation towards choice making. The demanding situations being faced by way of HR nowadays are an excessive turnover fee, low performance, absenteeism, recruitment of the proper applicants, workforce forecasting and 'Tony more. every passing day every challenge is turning into extra excessive. The excessive turnover charge is one of the utmost volatile factors in any company. If turnover rate may be projected accurately then it will resource in better future personnel planning. this can useful resource the HR managers to dewlap better repayment and blessings packages therefore decreasing worker turnover. on the grounds that every variable of HR is interrelated, understanding the motive and effect of one trouble can assist tool answers to all of the others. knowledge human behavior has usually been the hardest task in an employer worker attributes, attitudes, process pride and many such different elements are although necessary in carrying out one's duty but cannot be quantified. Overlooking these factors can spell doom for the agency. however, it's far a large mission for the FIR department to control these elements as these are crucial factors and one is aware of that if it cannot be quantified then it cannot be controlled. subsequently quantifying, measuring and controlling these elements holds the key to a better group of workers performance. With the emergence of latest IT based technologies like HR analytics, quantifying the HR factor is now viable. HR Analytics has helped agencies to mine the previously unquantifiable HR facts to derive a gold mine of HR intelligence which may be used to optimize the important thing performance indicators for this reason riding performance.

\section{HR Analytics}

Globalization and converting enterprise dynamics these days has increased the tasks to HR and the control on how to exceptional improve and use an agile and notablycompetency staff imply whilst upholding the value efficiency. modern enterprise demanding situations claim greater than just greater efficiency within the HR branch and an HRM shape. as an alternative, they necessitate expanded performance won thru a comprehensive know-how of the factors using a group of workers performance. organizations need to understand the complicated interplay between staffing degrees, abilities, reimbursement advantage systems, personnel profile, and further elements to assist them to maximize their return on human capital. HR analytics or workforce analytics aids the companies to make personnel decisions by means of lowering the fees, figuring out the revenue streams, mitigate risks, and execute effective business techniques. HR analytics empowers the HR managers with correct predictive analytics which determines the future, in particular for the companies looking for an extra proactive function in riding business method. HR Analytics permits the HR Managers to make human capital decisions that affect the business outcomes. consequently, it enables the HR to be extra engaged within the method of the company strategy. The various challenges of HRM can now be addressed with the assist of HR Analytics. HR Analytics offers the HR the tool that gives the insights which are required to expand contribution on the approach desk. as the demanding situations develop in this changing economy HR Analytics transforms the HR department with complete automation. HR Analytics rework the uncooked FIR records into the insightful statistics to the strategy components then eventually to shape an extremely good innovation. HR analytics aids to move the corporation ahead and slive ahead of the opposition by capitalizing at the insights received. HR analytics builds aggressive benefit by using producing actionable business intelligence at the "human beings side" of the business. HR analytics is assisting the corporations in renovating the Human assets from being tactical aid function right into a approach: companion (Smith. T, 2013).

\section{HR Analytics Transmuting Human Aid Management}

Organisation International today were the use of HR analytics software to boom the workforce performance. The deluge of HR records is the assets of facts that enable the executives an unheard-of capability to apprehend their personnel and agencies, assume demanding situations and opportunities. in the article How HR Analytics can remodel the place of business (Nemey, C. 2014), explain: how the capability to capture records and studying them has helped the organizations to both increases the revenues through higher understanding and precisely targeting customers and cutting prices via the progressed commercial enterprise manner. He also says that ITR managers are actually in a position to analyze mountairts of established and unstructured records too. answer the crucial questions regarding work-pressure productivity, the impact of training programs on overall performance, predictors of attrition and additionally able to discover the capacity leaders of the organization. in this intense aggressive market, every company has to stand wonderful quantity of demanding situations in front of them. these dilemmas can now be overcome with the brand-new reducing facet generation viz. HR Analytics that allows the HR managers to take a reality based choice supported through information based totally evidence. The usage of HR Analytics, Senior HR management can now justify the investments made to the human resource tasks and also are expecting destiny outcomes. hence HR analytics is the dawn of the brand-new era for Human aid management for overcoming its essential problems and challenges. So as to determine how HR Analytics has converted the world of Human useful resource control few case research may be analyzed. 


\section{Case-I: - A Case Examine of Manitowac (Source: Paleton Group, Case Study)}

For more than a century, The Mani to was organisation has been on the cutting edge of gadget manufacturing. This multibillion dollar organisation, with operations in over 26 countries across the globe, grew and outpaced its competition over the last few years in spite of a tough economy. similar to maximum corporations, Manitowac is faced with eventual retirement of many employees in strategic task classes, inclusive of engineering and production operations. To anticipate and put together for the recruitment, and ensure an orderly transition of the intuitional expertise from the skilled personnel to the brand new hires. even though the enterprise makes use of PeopleSoft 8 . nine as its FIR control device, it did now not have the reporting competencies required to color a complete image. As an end result, the FIR team needed to manually pull facts from the PeopleSoft and a large number of other source structures to provide complete visibility to the govt team's inquiries. To help the continued strategic planning process and advantage easy get admission to key HR metrics, the team determined it required an improved FIR reporting and analysis platform. The essential achievement factors for those initiatives protected: implement a precious section I solution by way of the case of 2012 .

a. Leverage current expertise and studies through preconstructed vendor answers.

b. provide flexibility to accommodate destiny tasks and enterprise wishes to.

c. Introduce statistics stewardship to provide consistency across all structures.

d. beautify architecture, guidelines, practices and tactics to manage the full data lifecycle.

\section{Solution}

In might also 2012, the agency's HR organization initiated the strategic HR analytics projects, and determined to implement Oracle's HR Analytics solution to satisfy its success criteria. To hit the tight cut-off dates, the implementation team applied a phased method, consisting of simple dashboard and reporting competencies handy through desktop and iPad. This allowed the group to answer immediate questions surrounding the staff profile, demographics and overall performance control. segment II and III included integration of Non- Oracle/ PeopleSoft HR information assets and deployment of greater advanced dashboard reporting and analysis capabilities. Leveraging Peloton's Nonaligned delivery methodology, the end users were able to provide feedback through active participation in regular modeling sessions. These Business adoption Model (BAM) session uncovered stakeholders to the often, providing them with heads-on, experimental learning and education before the solution went live. This helped to ensure that the solution was closely personalized to the executive team's needs, and that both the business and IT stakeholders had a clear understanding of the solution.

\subsection{Benefits}

Executives now have on-demand access to up-to-date HR information aggregated across business units. They are able to better manage their workforce by having faster access to accurate data. The HR team is focused on providing value added insight not just a collecting data and building reports. By leveraging oracle's HR analytics solution and focused implementation methodology, the team was able to hit their tight execution timeline. Finally the company now has a robust analytical infrastructure and architecture to build upon, and confirm it closely manages its talent pool to preserve its leadership position.

\subsection{Evaluation of Case - I}

From the above case, it can be inferred that Manitowoc became facing talent management troubles. due to the periodic retirement of many employees at strategic position and degrees, the company became going to lose quite a few to be hard to replace. Recruiting of recent employees and scouting them was sure not an easy task and especially a clean task and in particular recruiting on tight timelines to maintain aggressive edge and leadership become the undertaking in hand. An evidence plan changed into required to tug this one 01 however because of it-themselves with new FIR analytics software and business models, and after its faultless implementation at all ranges as intended, the cease users found themselves updated and the employer was abic to higher role themselves to forecast future requirements of manpower. The FIR crew was able to manipulate their work 3 higher due to fast accessible data and feature better expertise management in the organization. there has been a partial overhaul of the old out of date HR fashions, approaches and practices with a purpose to make way for a slicing facet, nation of the artwork HR. modeling and statistics management structures which had the capability to absolutely remodel the corporation's fortunes for the higher. today's HiZ analytics solutions blended with the existing people control software turned into the sports changer in this situation because it combined the already current and the more familiar control structures with a proper and systematic method in the Rom of the present day in the enterprise's Oracle's HR analytics solution. It also proves the very old adage in enterprise and enterprise that infusion of the traditional and the slicing facet always works miracles tier the agency specifically while implemented in a deliberate, systematic and in a phase clever manner.

\section{Case II- A Case Look at of Techno Inc. (Source: People Fluent Aquire Case Girl) Review Tenneco}

A main global manufacturer of auto parts, became 
spinning their wheels with manual organizational reporting and control succession planning procedures. They used People fluent's Org Publisher and Succession answers to immediately locate essential employee statistics and shorten their succession planning cycle. Mission With approximately 24,000 employees serving clients from dozens of strategically placed manufacturing and research centers around the sector, Tenneco is the main provider of emission and analysis OF CASE eleven: Tenneco became tying an expertise management problem as it far unfolds across many nations arid the $\cdot$ of outdated methodologies and approaches in FIR changed into adding to their woes. To be specific, aspirational document it and succession making plans flank became hit badly as they were manually looking to preserve databases across places with out a coordination with the valuable HR team in any way. no person became privy to the HR assets that they'd for an impeccable succession planning for great* position and ranges which also includes the pinnacle brass. backside line, agency's future become in jeopardy along with a shaky modern HR branch which became straining. resources to make ends meet. 13ut, with a dedication to straight away cope with those burning issues, the corporation's HR came up will the introduction and implementation of the People Fluent's Org Publisher and succession which changed into a tailor-nixed strategy to the database compilation, upkeep and org chart writer as well as a readymade tool for addressing the succession making plans problem. It became intelligently included across all places to pool within the entire information with the intention to make it effectively to be had whilst requested. All records in those databases across all locations were synchronized as properly. no longer most effective the information become accumulated and from one-of-a-kind databases across locations but it becomes additionally classified consistent with the enterprise's necessities and also resides mean 6 dtil as what massive information management structures are speculated to do. This mean and greater sensible statistics diverse with the desired metrics now might be used for success for crucial roles throughout the company at numerous managerial levels which previously regarded as a far-off dream. Implementation and integration of the modern HR analytics into the HR systems and databases helped Tenneco overcome the reporting and succession making plans issue fashion and just in time to streamline such indispensable procedures. (case take a look at, 2010)

\section{Conclusion}

From the evaluation of the above two case studies, it may be concluded that the problems which the 3 groups were going through have been diagnosed and resolved with the assist of HR Analytical software program. The troubles of HR viz. succession planning, recruitment, manpower planning, forecasting of turnover etc. all can now be solved with the brand-new era of HR analytics. HR analytics has helped the companies to improve their overall performance with the aid of creating a network of individuals to characteristic as a strategic associate. The modern day questioning and data at the HR implications has proved to be a worldwide discussion board for the Human aid branch. if Someone want to live as a marketplace leader, clean techniques and new innovations are required. in the age of Analytics, skills represent the last real competitive facet for groups nowadays. So, why HR place needs to be logged in the back of. HR analytics is helping the Human useful resource Managers to end up genuine strategic leaders. hence HR analytics is Transmuting the Human resource department and the HR managers to function more as commercial enterprise companions and achieve organizational fulfillment. HR Analytics has certainly facilitated the development of a body of workers performance in a company for this reason growing the productivity of the personnel in turn increasing revenue era.

\section{References}

[1] A. Banerjee, T. Bandyopadhyay and P. Acharya, "Data analytics: Hyped up aspirations or true potential", Vikalpa, vol. 38 , no. 4 , pp. 1 - 11, 2013.

[2] Aquire (2010). Case study of global pharmaceutical industry supplier uses acquire solution to port vital Oracle hr database informant ion to employee Intranet, Retrieved on 27th March 2015 from http://www.aquire.com/iresourees/day II/Ides/583936z 5320511/_fn/Colorcon+Case+Study.pdf

[3] D. Vesset, B. McDonough, C. W. Olofson, D. Schubmehl, A. Woodward, S. Bond and M. Wardley, "Worldwide Business Analytics Software Forecast, 2015-2019", www.idc.com, 2015. [Online]. Available:

https://www.idc.com/getdoc.jsp?containerId=257402. [Accessed: 14- Dec- 2015].

[4] De Cen 70, 1), 1 id, A. \& Robbins, Stephen, R. (1996), Human Resource Management, NY: John Wiley \& Sons.

[5] E. E. Lawler III, A. Levenson and J. W. Boudreau, "HR metrics and analytics-uses and impacts", Human Resource Planning Journal, vol. 27, no. 4, pp. 27 - 35, 2004.

[6] E. Lawler and J. W Boudreau, "What makes HR a strategic partner", People and Strategy, vol. 32, no. 1, pp. 14 - 22, 2009. x. T. H. Davenport, J. Harris and J. Shapiro, "Competing on talent analytics", Harvard Business Review 88, no. 10, pp. 52 $-58,2010$.

[7] HR Joins the Analytics Revolution", 2015. [Online]. Available: https://hbr.org/resources/pdfs/comm/visier/18765_HBR_Visie r_Report_July2014.pdf. [Accessed: 11- Sep- 2014]].

[8] Ili we Waterhouse Coopers (PwC), (2014), Trends in work force wilily tics: capturing the latest results for US Human Capital Elkvtieeness Benchmarks, 2014, Survey Report, Retrieved from http://www.pwc.conVen_US/us/hr management "Publications/asset s/p wct rends-in-workforceanaly t ics.pdf

[9] J. Harris, E. Craig and D. Light, "Talent and analytics: new approaches, higher ROI", Journal of Business Strategy, vol. 32, no. 6, pp. 4-13, 2011. v. S. Pemmaraju, "Converting HR data to business intelligence", Employ. Relat. Today, vol. 34, no. 3, pp. 13-16, 2007. 
[10] J. Lukić, "The impact of information and communication technology on decision-making process in the big data era", Megatrend revival 11, no. 2, pp. 221 - 234, 2014.

[11] J. W Boudreau, "Talentship and HR measurement and analysis: From ROI to strategic organizational change", People and Strategy, vol. 29, no. 1, p. 25, 2015.

[12] K. D. Carlson and M. J. Kavanagh, "HR metrics and workforce analytics", in Human Resource Information Systems: Basics applications and future directions., 1st ed., M. J Kavanagh and M. Thite, Ed. Thousand Oaks, CA: Sage Publishing, 2012, pp. 150 - 174.

[13] Petition group (N. A), A case study of Manitowoc, Case Studies of HR Analytics Workforce M management with better Insights, Ret Rio cd on 20th August 2015 from http://pelotongroup.comiclients-and-insights/case-studies/hranaly tics/

[14] Reoplelluelit Aquire (NA), A case study of people fluent solutions drives Techno to HR success, retrieved on 15 th February 201 turn www, iquire.com

[15] S. Mondore, S. Douthitt and M. Carson, "Maximizing the impact and effectiveness of HR analytics to drive business outcomes", People and Strategy, vol. 34, no. 2, pp. 20-27, 2015.

[16] T. H. Davenport, and J. G. Harris, "Competing on Analytics: The New Science of Winning". Harvard Business Press, 2007. 